\title{
Tracing Post-Dvaravati Culture from Space: Applying Remote Sensing Technique in West-Central Thailand
}

\author{
(Q) (O) (O) \\ PODJANOK KANJANAJUNTORN, SUPAMAS DUANGSAKUN, \\ BUDSABA UAMKASEM, AND RAMPHING SIMKING
}

\section{INTRODUCTION}

The application of SPATial technology to arChaeological ReSEARCh in Southeast Asia is increasing (CRMA 2012; Mackay and Sullivan 2008; Pryce and Albrams 2010). Countries such as Thailand have made this sophisticated technology available for research in the social sciences and humanities. Archaeology is one of the disciplines that benefits. Remote sensing technology can yield detailed information on the history of the landscape that often leads to an understanding of human activities. Satellite images and aerial photographs can reveal previously hidden archaeological features and help identify archaeological sites, specifically ancient features such as earthworks and ditches. Such imagery provides visual information relevant to the history of the natural and cultural landscape.

Archaeologists in Thailand have often been attracted to those areas where there has been immediate evidence of monument ruins. Historical sites with less noticeable features have thus received minimal attention. For example, the archaeology of westcentral Thailand during the Lopburi period of the eleventh through thirteenth centuries has suffered from this lack of attention. West-central sites of this period tend to contain relatively subtle archaeological features, making it difficult to perceive larger patterns during ground surveys. Evidence thus remains fragmentary for the historic period starting with the decline of Dvaravati after the eleventh century, by which time economic power had moved to other parts of Southeast Asia. Studying this regional history is important to understanding pre-modern Thailand before the rise of Sukhothai, classically treated as the heart of "Thai" national history.

Podjanok Kanjanajuntorn is a Lecturer in Archaeology, Faculty of Sociology and Anthropology, Thammasat University, Thailand; Supamas Duangsakun is an Archaeologist with the Second Regional Office of Fine Arts, Suphanburi, Fine Arts Department, Thailand; Budsaba Uamkasem is a Geo-Informatics Scientist with the Geo-Information and Space Technology Development Agency (Public Organization), Thailand; Ramphing Simking is Director of the Product Development Center, Geo-Information and Space Technology Development Agency (Public Organization), Thailand.

Asian Perspectives, Vol. 53, No. 1 (C) 2015 by the University of Hawai'i Press. 
Despite the discovery of major sites such as Prasat Muang Singha and Wat Kamphaeng Laeng in the study region, the culture and history of this period is as yet poorly understood. Additionally, the fact that most of the historical monuments in the region resemble the thirteenth-century Khmer Bayon style has triggered controversy about the nature of the political and cultural landscapes of the period. The question is whether the monuments indicate that the political influence of the Khmer kingdom extended to its western extremity during the reign of King Jayavarman VII or whether they are merely evidence of cultural influence. Having insufficient archaeological data has made it impossible to resolve this question.

The research discussed in this article contributes significantly to archaeological data for the region and sheds some light on the early history of west-central Thailand, while providing a more detailed picture of the overall socioeconomic development of Mainland Southeast Asia during what was a significant period of expansive premodern states and empires. We identify cultural characteristics that can be used to distinguish Lopburi materials from those of other regions and periods. A particularly significant contribution of this project is the discovery of what we believe to be the precise location of Suvarnapura, a town mentioned in the Cambodian Prasat Phreh Khan inscription. The location of this town has been hotly debated by scholars.

This study focuses on the west-central region including the provinces of Nakorn Pathom, Kanchanburi, Petchaburi, Ratchaburi, and Suphanburi, during the period between the eleventh and thirteenth centuries (Fig. 1). The objective of our research was to search for new sites and examine archaeological evidence using recently introduced technologies for site detection and mapping that allow for both larger scale and more detailed resolution. Such higher quality images should enable us to address cultural relationships between regions. We attempted to identify features of all sizes using available aerial photographs and high-resolution satellite images. It has been a challenge to use remote sensing technology for this particular period because, although already-known major sites were readily identifiable in remote imagery, subtler archaeological features were not always apparent. We therefore also relied on conventional field survey methods to confirm the existence of less obvious sites from the ground.

Aerial photographs of early date are useful because they provide topographic information on the landscape that is less affected by exponentially increasing modern landscape destruction through intensified farming practices, urbanization, road building, and even purposeful site looting. Satellite images, on the other hand, captured more recently and yielding higher quality images, can provide detailed information of the landscape at a high resolution, which can be useful in both locating sites that are not apparent in the lower precision aerial photos and guiding investigations in the field, such as detailed ground mapping and test excavation. A comparative study of archaeological evidence from site survey and excavations, including artifacts and archaeological features, is also an important component of the work presented here. However, in terms of the scope of analysis in the present article, the discussion focuses on the cultural landscape as evidenced in the archaeological remains themselves and not iconographic interpretations. Analysis of iconography is not the main concern in this study, since such matters have already been extensively studied elsewhere (Juntawit 1986; Suksvasti 1987a; Vallibhotama 1983).

This article is divided into three parts. First, we review previous research and debates about the west-central region of Thailand after the decline of Dvaravati (c. A.D. 


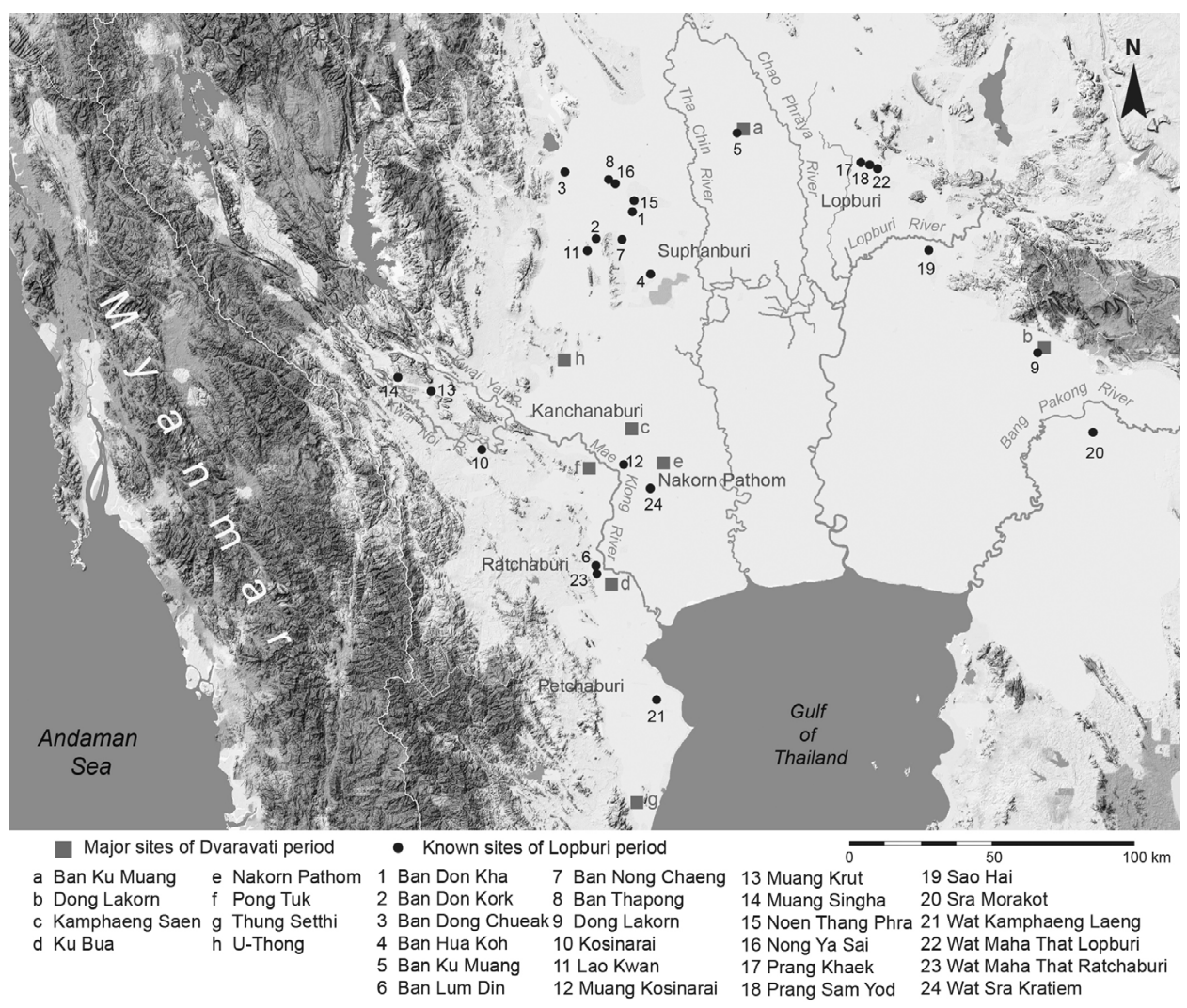

Fig. 1. Map showing locations of major Dvaravati-period sites and known Lopburi-period sites discussed in this article (base map from Google Maps).

700-1000). Then we discuss the application of remote sensing technology to identifying historical sites in the study region. Finally, we analyze the cultural, political, and economic roles of the study region in the historical Lopburi period.

\section{THE SUCCESSORS OF DVARAVATI IN WEST-CENTRAL THAILAND}

The reasons for and date of the decline of Dvaravati in west-central Thailand have been much debated. Current archaeological evidence indicates a decline in the economy and changes in settlement patterns. From these archaeological indicators, scholars have proposed that Dvaravati declined because of an outbreak of a pandemic that forced people to abandon their residences (Damrong Rajanubhab 1954). Major Dvaravati moated sites such as the ancient town of U-Thong have not yielded any significant evidence of occupational continuity after the eleventh century. However, an area north of U-Thong in what is now the Muang Suphanburi and Don Chedi districts has produced significant antiquities, including religious monuments and artifacts related to religious beliefs (Opakul 1973, 2000).

The chronology of Dvaravati is uncertain. Archaeologists have not been able to define this historic period satisfactorily (Barram 2003), an issue that is not helped by the broad chronology of the Lopburi period in this region. While art historians 
might be able to determine a more accurate chronology based on time-sensitive art styles from well-established contexts, the contexts of most of the sculptures remain unknown. Moreover, although comparative dating of regional sites based upon architectural and sculptural styles can provide a precise time period, it is rather restricted. On the other hand, artifacts such as potsherds suggest a rather broad occupational period, given that various types of potsherds dating from the eleventh to the fourteenth centuries are sometimes found at the same site. Archaeologists could resolve the problem of archaeological mixing of time periods due to natural or cultural processes by providing careful attention to details of archaeological contexts and reconstructing the processes that created them in future excavations. That is, future excavations could improve the situation.

Another significant debate in the historical archaeology of Southeast Asian archaeology is the spatial extent of the political and/or cultural territory of the Khmer Empire. Most scholars agree that some areas east and northeast of modern Thailand were part of the Khmer Empire (Briggs 1951). Several ancient texts also refer to a Khmer invasion of Pagu and Thaton in southern Myanmar (Briggs 1951 :169). The thirteenth-century Chinese record of Chau Ju-Kua listed Pagan as one of the dependencies of the Khmer. However, it has been suggested that Chau Ju-Kua's record was inconsistent and that it was unlikely that the powerful state of Pagan would have come under Khmer rule. Possibly he mistook Pagan for Pagu because the names were similar (Hirth and Rockhill 1911:54, 56). Due to a lack of objective evidence, some scholars doubt the Khmer Empire ever expanded into Myanmar (Vallibhotama 1981). Khmer influence was likely intermittent in such remote areas.

According to inscriptions, the Khmer king Jayavarman VII was a significant figure in the thirteenth century who imposed his power upon neighbors in ways that might still be visible on the landscape. His ambitious projects, outlined in many inscriptions, included commanding the construction of 102 arokayasalas (hospitals) and 121 dhammasalas (lit. houses of fire; resthouses) on routes between Angkor and five major destinations. These provided accommodation and aid for Buddhist pilgrims (Kaeoklai 1985). ${ }^{1}$ Each arokayasala and dhammasala site included a monumental tower (sukkatalai) erected with stones and lateritic bricks. Pilgrims worshipped sacred statues contained in these towers.

The way King Jayavarman VII is portrayed in inscriptions, especially his commissioning sacred statues to be built throughout the empire, can be interpreted in various ways. It can be seen as an act of kindness by a royal patron in his role as Dhammaraja to his subjects. ${ }^{2}$ Alternatively, it can be seen as a symbolic act intended to reinforce the imposition of power and authority over distant territories. Furthermore, the actual numbers of arokayasalas and dhammasalas discovered so far are inconsistent with the numbers specified in the ancient texts. Moreover, as can be observed at several sites in northeast Thailand, some monuments appear to have remained unfinished. ${ }^{3}$

While plenty of arokayasalas and dhammasalas dating to the thirteenth century have been found in northeast Thailand, no religious monuments of these types are found in the west-central region. Piromanukul (2004) believes these two types of construction have not been found in west-central Thailand because this region was not part of the Khmer Empire. However, other scholars intrepret the Bayon-style architecture and religious sculptures such as the radiating Avarolikesvara found in west-central Thailand as at least indicating acceptance of Khmer political power (Piromanukul 2004:33-35). 
Lopburi-period religious centers in the west-central region of Thailand have been identified at Muang Singha, Muang Petchaburi (Wat Kamphaeng Laeng), Muang Kosinarai, and Muang Ratchaburi (Wat Maha That). These large walled sites, which perhaps can be referred to as ancient towns, all have religious monuments situated at or near their centers. These monumental remains and their associated objects have been recognized as having been influenced by the Khmer culture of the Bayon period, dated to the thirteenth century, around the time that Mahayana Buddhism was being practiced throughout the Khmer Empire (Damrongsiri 1988; Finot 1966; Mankhong 1995; Wilaikaeo 1991). These historical sites were undoubtedly influenced by ancient Khmer construction practices. Traditional Khmer site layouts followed strict cardinal orientations. Likewise, the walled sites in west-central Thailand of the Lopburi period are all rectangular or almost square and aligned east-west and northsouth. Their boundaries were formed by earthworks or brick walls and ditches, ranging from 700 to $1000 \mathrm{~m}$ in length and width, with each site's length typically similar to its width.

The religious monuments at their centers were constructed from laterite bricks and decorated with plaster and stucco. Some of the stucco motifs bear a resemblance to the Dvaravati style (FAD 1987; Juntawit 1986) (Fig. 2). More importantly, rare specimens of radiating Avalokitesvara, the statue of worship related to Mahayana Buddhism, have been discovered at Prasat Muang Singha, Wat Kamphaeng Laeng, and Muang Kosinarai (Fig. 3).

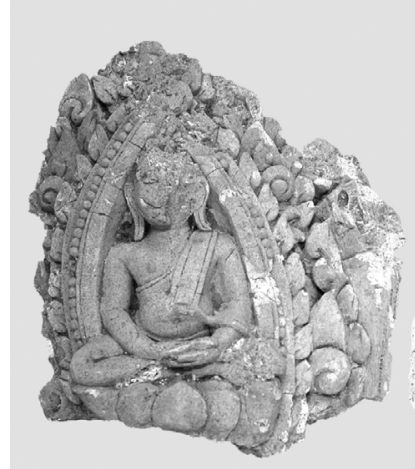

a.

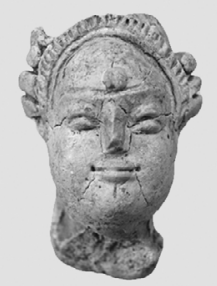

c.

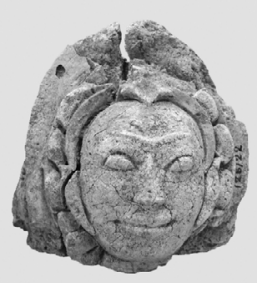

d.

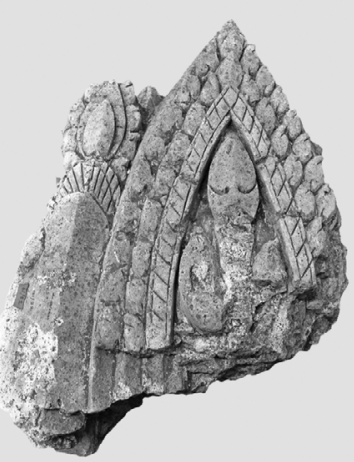

b.

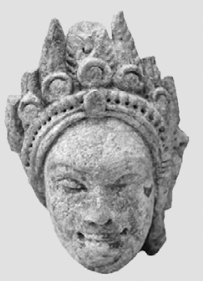

e.

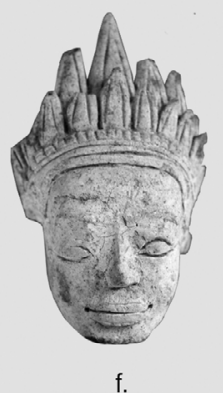

f.

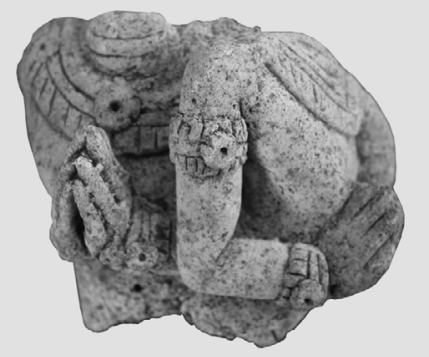

h.

Fig. 2. Stucco motifs and other decorative items found at Noen Thang Phra (a.-e.) and Muang Kosinarai (f.-h.). 


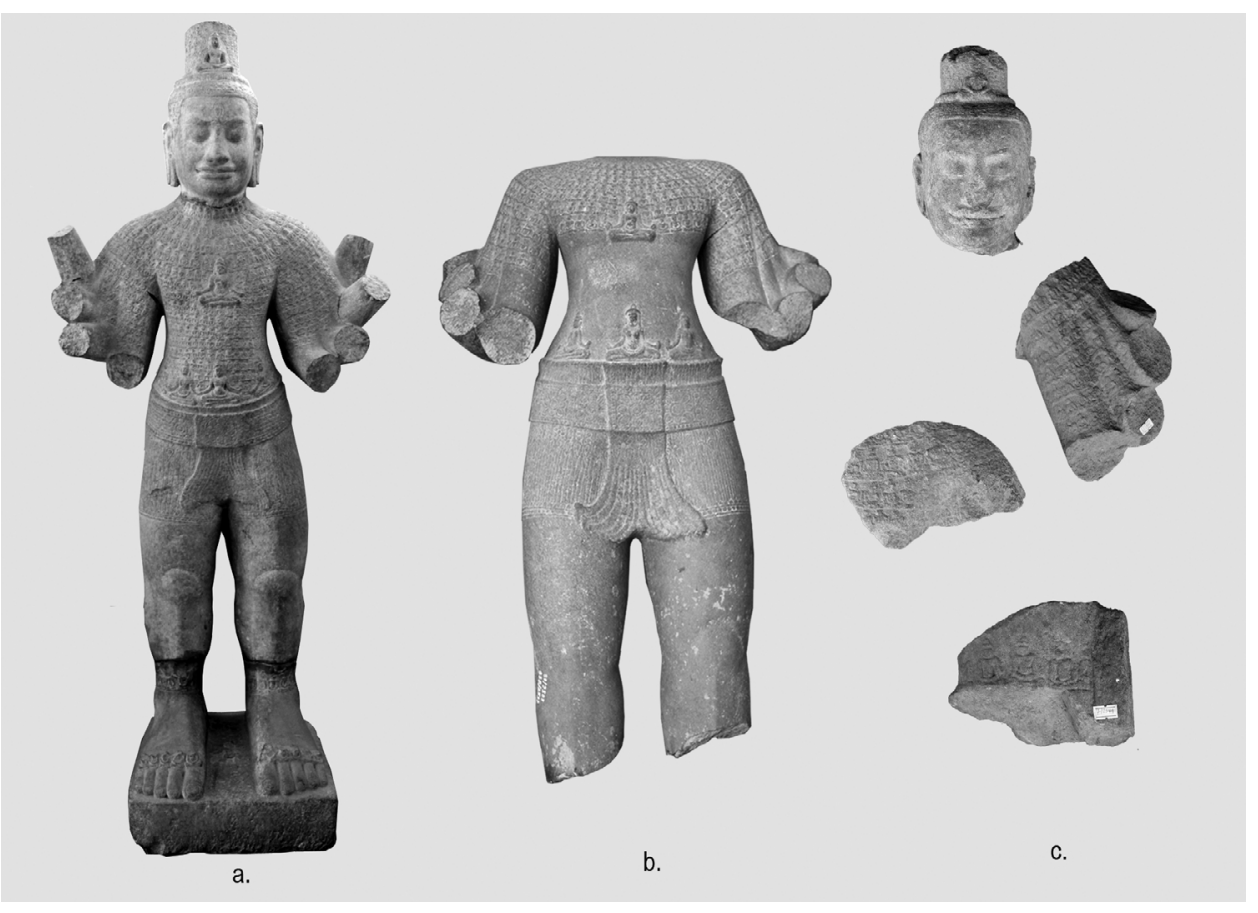

Fig. 3. Radiating Avalokitesvaras found at Prasat Muang Singha (a.), Muang Kosinarai (b.), and Wat Kamphaeng Lang (c.).

These finds have contributed to a debate about the extent of King Jayavarman VII's influence in this part of Thailand and whether this influence was simply a result of cultural interaction or if it was an indicator of political submission. There are certainly different views on what such structures mean in terms of actual political control versus cultural influence by the Khmer (Theerajaruwan 2009). Some scholars believe that it was nothing more than cultural influence, since they do not see what they consider direct evidence of political domination (Vallibhotama 1983, 1997). Other scholars have offered a different analysis, suggesting that the Khmer must have imposed political control over west-central Thailand for at least a short period of time (Chiachanphong 1987; Piromanukul 2004; Suksvasti 1987b). The Khmer may have extended influence over this region for economic reasons such as acquiring natural resources, as well as for political purposes such as controlling the territory as protection against more remote groups farther west. It remains difficult to determine the time span or estimate the extent of the influence or what impact the Khmer had upon society in the west-central region.

Textual scholars believe that west-central Thailand was mentioned in an ancient temple inscription at Prasat Phreah Khan. This ancient text refers to a royal command by King Jayavarman VII to build Jayabhuddhamahanatha statues in twenty-three towns, including places named Suvarnapura, Sri Sambukapattana, Sri Jayarajapuri, Sri Singhapuri, and Sri Jayavajarapuri (Diskul 1966:56). Some of the place-names mentioned in the inscription have not been identified because the text does not provide much information, but scholars agree that these five places really existed and are 
equivalent to today's Suphanburi (Noen Thang Phra), Muang Kosinarai, Muang Singha, Muang Ratchaburi (Wat Maha That), and Muang Petchaburi (Wat Kamphaeng Laeng), respectively (Suksvasti 1983b) (Fig. 1). ${ }^{4}$ Suksvasti (1983b) suggests the place-names appeared in the text in order of their distance from Angkor. Thus, Lavapura (modern Lopburi) comes before the five towns listed above as one moves westward.

Most of these ancient towns were walled, with the exception of Suvarnapura (modern Suphanburi). Some scholars believe that the center of Suvarnapura is at the site of Noen Thang Phra approximately twenty-five kilometers north of the Muang Suphanburi district. Unfortunately the site is in poor condition. It was abandoned, and became unused land in the middle of paddy fields; it was also severely looted many years ago. The Fine Arts Department (FAD) of Thailand undertook a rescue excavation and obtained concrete evidence for its general chronological and cultural associations with the other sites, including a life-size four-armed Avalokitesvara and carved stone heads of presumed guardian figures (Vallibhotama 1983). Despite the site's condition, it has been considered a significant site because of the outstanding archaeological finds there, particularly sculptural remains. In the next section, we review this site and argue that it was unlikely to have been the center of Suvarnapura.

One has to rely upon foreign texts because, although a number of inscriptions have been discovered from the Dvaravati period, there is very little textual evidence from the Lopburi period in the west-central region. So far only one piece of written evidence has been discovered in the region-from Prasat Muang Singha. The text was inscribed on a piece of sandstone with a square sculptural base. It refers to someone named Phraya Chaiyakon, who may have been a member of the elite involved in local administration (Weeraprajak 1987). While deciphering the inscription, Weeraprajak noted that the alphabet was unlike that of normal thirteenth-century ancient Khmer. He considered the possibility that it was an early version of a Thai script derived from Khmer. Other scholars argue that the script is actually a form of ancient Khmer dated to the post-Angkor period of the late thirteenth century (FAD 1987). This argument seems to have influenced some scholars who believe the temple at Prasat Muang Singha should be dated to the post-Bayon period in the second half of the thirteenth century A.D. If so, the monument would have no relationship with the reign of King Jayavaraman VII, but instead be an imitation of an earlier style of high art. An additional explanation, which notes a discrepancy in dating between textual-based interpretations and archaeological materials at the site, is that the artifacts at the site date to the Bayon period, but had been moved to this site at a later time (FAD 1987). We consider this rationalization to be overly simplistic, however.

Other written evidence about the west-central region includes a tenth-century Sanskrit inscription on the base of a statue of a standing Buddha found at Wat Maha That in Lopburi Province. Although the statue and its inscription are dated to the Dvaravati period, earlier than the Lopburi period that concerns us here, this textual evidence is still relevant because it mentions that a son of a monarch from Sambuka ordered a standing Buddha to be built (FAD 1986). Sambuka coincides with the place-name Sambukapattana, mentioned in the thirteenth-century Khmer inscription from Prasat Phreah Khan discussed above (OPM 1970). Sambukapattana is believed to be the walled site of Muang Kosinarai in Ratchaburi Province. There is another major Dvaravati site nearby, Pong Tuk, located a mere eight kilometers to the northwest, up the Mae Klong River. It is reasonable to assume that two similar names, Sambuka and 
Sambukapattana, mentioned three centuries apart are actually the same place. If that is the case, the inscription from Wat Maha That in Lopburi could indicate that a polity named Sambuka existed and even had a relationship with Lavapura (Lopburi) during the Dvaravati period.

Many monumental sites are now in poor condition. Brick fragments and minute stucco remains have been found scattered on the surface of agricultural lands, while in other cases ruined sites have become the holy ground of modern temples in which old bricks and ponds have been re-used. Under such conditions of disturbance by modern activities and re-use of ancient building materials, reconstructing architectural style is problematic. Nevertheless, the fact that large walled sites and monumental buildings have been found in west-central Thailand indicates that there was a significant population and that considerable wealth was accumulated by local elites during the Lopburi period. ${ }^{5}$

It is likely that economic centers other than these known walled sites have yet to be discovered because of the archaeological focus on architecturally visible sites. Unfortunately, most monumental sites were looted decades ago. Looted sites have been reduced to rubble and the original locations of monuments are often not known, let alone their range of architectural styles and decorations. Despite the problem of artifacts having been removed from their original contexts, the provenance of these ruins at least indicates the proximity of ancient communities.

Fieldwork using remote sensing technology has the potential to reveal more archaeological information about the overall size and spatial organization of ancient religious centers, the relationships between monumental features, areas of disturbance that might indicate hidden features, and the relative locations of artifact concentrations of various types. The next section of this article outlines our fieldwork methods and findings. We then discuss the contribution of remote sensing technology to our understanding of the political dynamics and cultural exchanges of the Lopburi period. ${ }^{6}$

\section{TRACING THE REMAINS OF ANCIENT CULTURES FROM SPACE}

The rest of this article focuses on sites from the Lopburi period in west-central Thailand that have not previously been properly recorded by professional archaeologists. New sites were discovered using a combination of methods. ${ }^{7}$ We began with the conventional method of systematic ground surveying. While archaeological researchers have attempted to locate and trace historical sites with landscape features such as earthworks, ditches, and ancient baray (ponds), excavations are expensive and timeconsuming and ground surveying does not always reveal the precise location of archaeological features. We therefore interviewed local people in an attempt to locate lesser-known sites. Local communities have long been aware of the existence of sites other than the well-known walled sites at Prasat Muang Singha, Kosinarai, Wat Maha That Ratchaburi, and Wat Kamphaeng Laeng. We also consulted nonacademic sources such as websites, magazines, and newspapers related to the amulet and antiquities trade. Some looted artifacts, particularly statues associated with worship and votive tablets, are presented in illustrations in antiquities trade magazines. Such media often provide site names or describe the types of finds recovered from looted sites. Nonprofessional amulet and antiques collectors often assign site names based on amulet artifact types. This means that the general geographic provenance of these 
types of artifacts can easily be determined. ${ }^{8}$ Local people we interviewed were also cooperative and helpful in providing information on the specific provenance of some antiquities.

Remote sensing technology has increased the possibility of discovering new archaeological sites and their features, although the extent and success of its use is dependent upon the specific characteristics of archaeological sites. In the region and period of interest in our research, the landscape included large-scale archaeological features such as earthworks and ditches, but these varied in size and visibility. Features greater than $600 \mathrm{~m}$ in length were easily recognized, provided they were in reasonably good condition. Where the landscape had changed rapidly, whether naturally or through human activities, some archaeological features had been transformed so much that they could no longer be recognized on the ground. A number of Lopburi-period features in west-central Thailand, mostly enclosures related to religious activities, range in size from approximately $150 \times 150 \mathrm{~m}$ to $350 \times 350 \mathrm{~m}$. These small sites were not easy to detect from the ground unless they were already known, but were still visible from the expansive view afforded by remote sensing technology.

We therefore analyzed visual data to identify archaeological features. We started by examining aerial photographs taken at the earliest date available. They provided the earliest possible remote spatial view of archaeological features and landscapes. Satellite images, however, offered higher resolution and more precise positioning of features on the ground. Both sources of spatial information were checked against each other, then cross-referenced with data obtained from field walking and interviewing informants.

This method allowed us to see the regional distribution of historical sites around specific landscape features such as river valleys. Importantly, there appear to be noticeable differences between sites found in the Tha Chin (also known as Suphanburi and Nakorn Chaisi) and Mae Klong river valleys. Our field survey identified various Lopburi-period sites clustered along the plain of the Tha Chin River and its tributaries, the Tha Wa River and Tha Koi River. The major monumental sites of Noen Thang Phra and Ban Nong Chaeng in Suphanburi Province were already known and both sites had already yielded significant finds. A large collection of statues and stucco decorations from the Noen Thang Phra monument are kept at the national museums in Suphanburi and U-Thong. Those from Ban Nong Chaeng can be seen at the museum in the Ban Nong Chaeng school near the site. However, it is believed that the most significant finds, comparable to those found in Lopburi Province in terms of their quality of craftsmanship, are held in private collections (Opakul 1973).

The site of Noen Thang Phra is now unused land in the middle of a paddy field. This site has been considered by some scholars to be the center of Suvarnapura, the ancient town mentioned in the Prasat Phreah Khan inscriptions discussed in the previous section. This assumption is based on the finds there being more elaborate and of higher quality than those at other sites in Suphanburi Province. Aerial photographs of this site taken in 1953 show features of a rectangular enclosure of only approximately $150 \times 120 \mathrm{~m}$, with a square-shaped feature in the middle, possibly a monument (Fig. 4). ${ }^{9}$ The monument has been reduced to piles of bricks so that its original shape is unknown. Although not much of the structure of the building can be seen, some decorated pieces found in the rubble have offered clues to dating and site function. Core stones of antefixes made from laterite covered with deteriorated plaster were identified during the field survey (Fig. 5). Corncob-shaped antefixes attached to the 


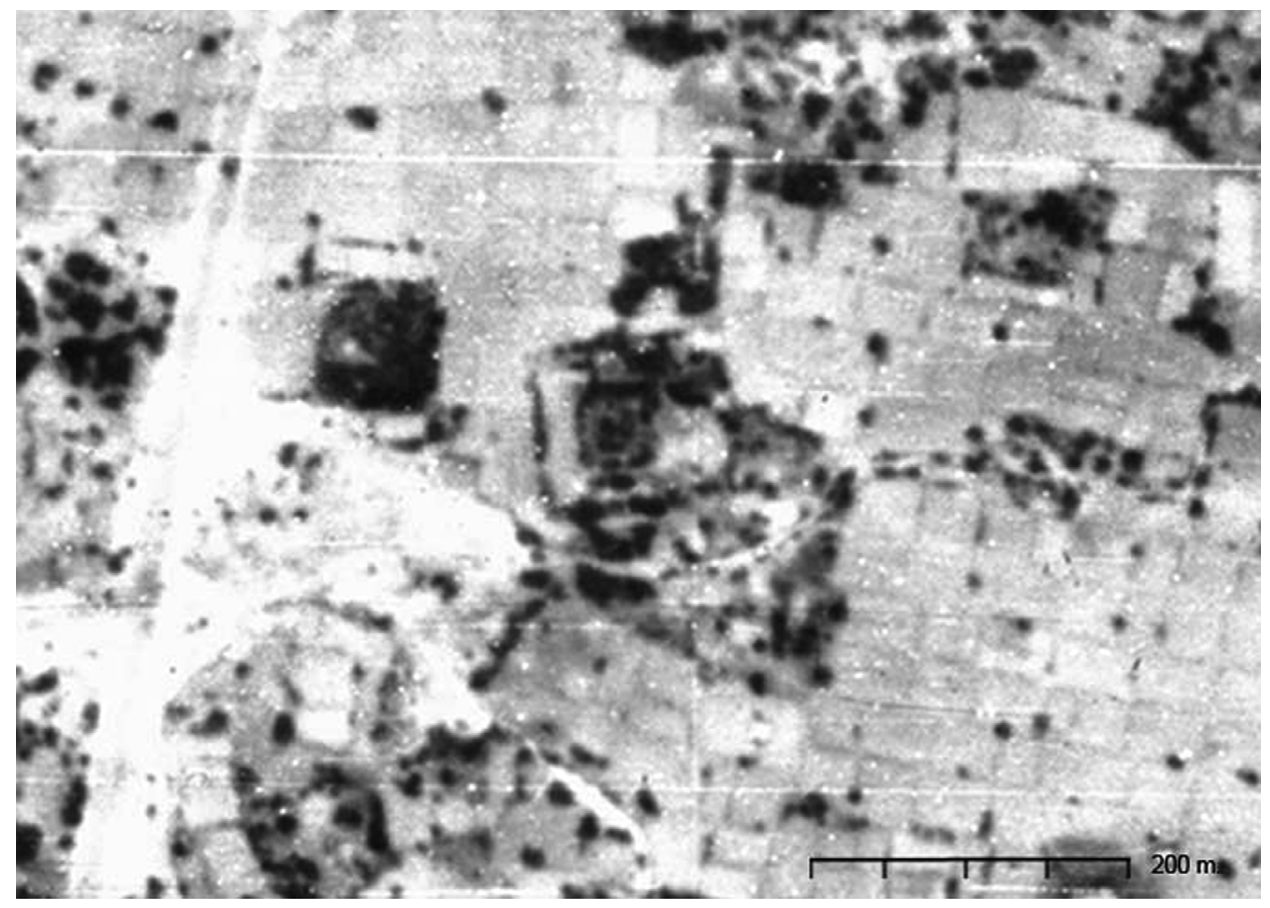

Fig. 4. Aerial photograph taken in 1953 of Noen Thang Phra (VV WWS M23 AMS 11 Feb 53, 119, 3102).

upper part of towers were typical architectural elements of the type of Khmer stupa (tower or building) called a prasat or prang. Some remains of stucco decorations bear a trace of the Dvaravati style of art, particularly in including human and animal figures. ${ }^{10}$ Though decorated in a local style, the religious monument at Noen Thang Phra was likely of the Khmer prang type.

Examination of the surrounding landscape showed another site slightly more than $4 \mathrm{~km}$ to the south called Ban Don Ka. The features of this site are similar in shape and size to Noen Thang Phra. An image of a Buddha protected by the hood of a naga has been discovered at the Ban Don Ka site (S. Duangsakul pers. comm. 24 May 2012). Such religious statuary is normally associated with religious monuments. The 1953 aerial photograph of Ban Don Ka reveals a feature comprised of a square enclosure. A small dark spot in the middle of the enclosure suggests there was once a monument of a similar size to the one at Noen Thang Phra.

Despite the impressive archaeological evidence previously found at Noen Thang Phra, we contend that the legendary town of Suvarnapura was unlikely to have been situated there. First, the overall structure of Noen Thang Phra, as revealed by the aerial photograph, was of modest proportions and there seem to be no other features on the ground. Second, aerial photographs do not show any features such as a walled site that would indicate there was a large community in the vicinity of Noen Thang Phra and Ban Don Ka. Recent satellite images of the area also do not indicate any other ancient man-made features. This visual information suggests that Noen Thang Phra was not important enough to have been the original site of Suvarnapura. 

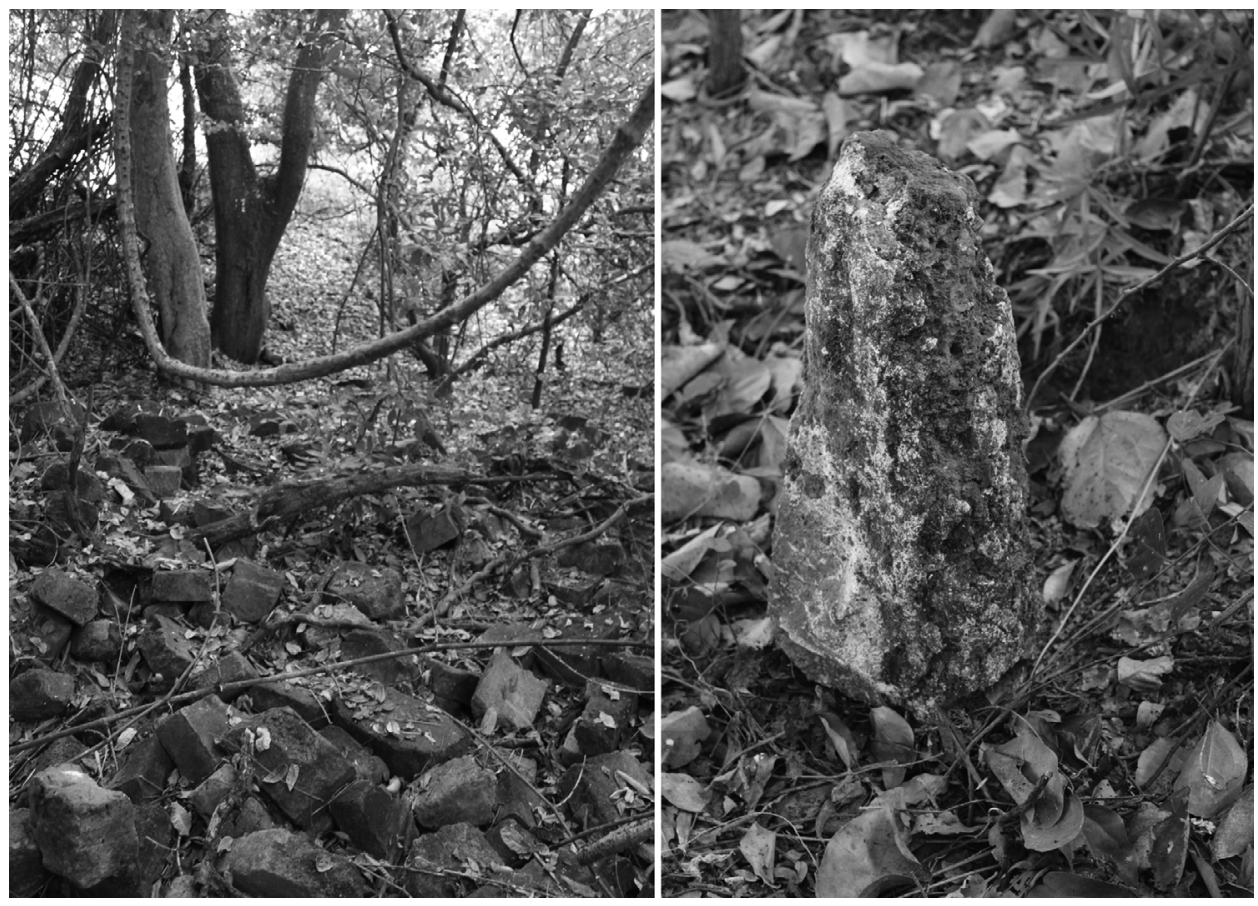

Fig. 5. Monumental ruin at the site of Noen Thang Phra (left); a piece of an antefix found at Noen Thang Phra (right).

We therefore looked for other sites where substantial archaeological features have been identified. According to information from the 1953 aerial photographs, the site of Ban Nong Chaeng includes many complicated features that covered a much larger area than the site of Noen Thang Phra (Fig. 6). The most prominent feature is a rectangular rampart, approximately $850 \times 820 \mathrm{~m}$ (Fig. 7). The earthworks on each side are clearly outlined, except for the southwest corner. The northern earthwork probably continued farther toward the east. In the middle of the enclosure, another line of earthwork construction oriented north-south ran about two-thirds of the length of the enclosure until it reached a mound.

The 1953 aerial photographs show other interesting features such as earthworks, ditches, and ponds outside the walled site, particularly to the east and south. The function of the earthworks is uncertain, but some of these features were likely structures comprising religious compounds. Unfortunately, the landscape of the site has been significantly altered. Parts of the rampart have been turned into roads, so effacing the structures and layout of the earthworks and ditches that they are now mostly unrecognizable.

Probably because they did not have access to a large-scale aerial view, the team at the Fine Arts Department of Thailand did not recognize that a large enclosure once existed at Ban Nong Chaeng when they investigated the site in 1965. Their report provided good descriptions of numerous monuments at the site, however (FAD 1965). According to a site plan attached to the report, monumental ruins were situated outside and to the east of the walled site. They identified clay bricks as monumental 


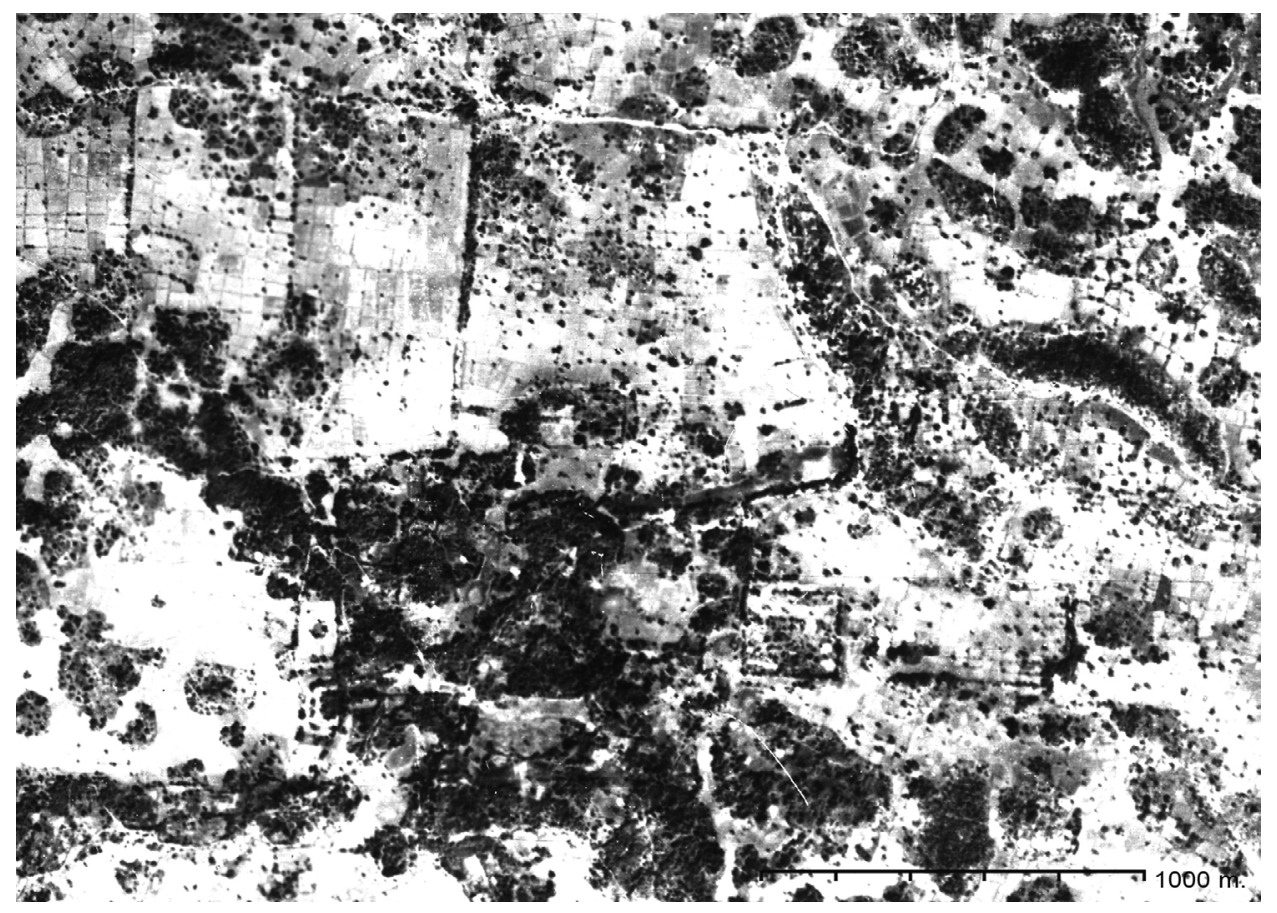

Fig. 6. Aerial photograph of Ban Nong Chaeng (VVWWS M23 AMS 11 Feb 53, 119, 3077).

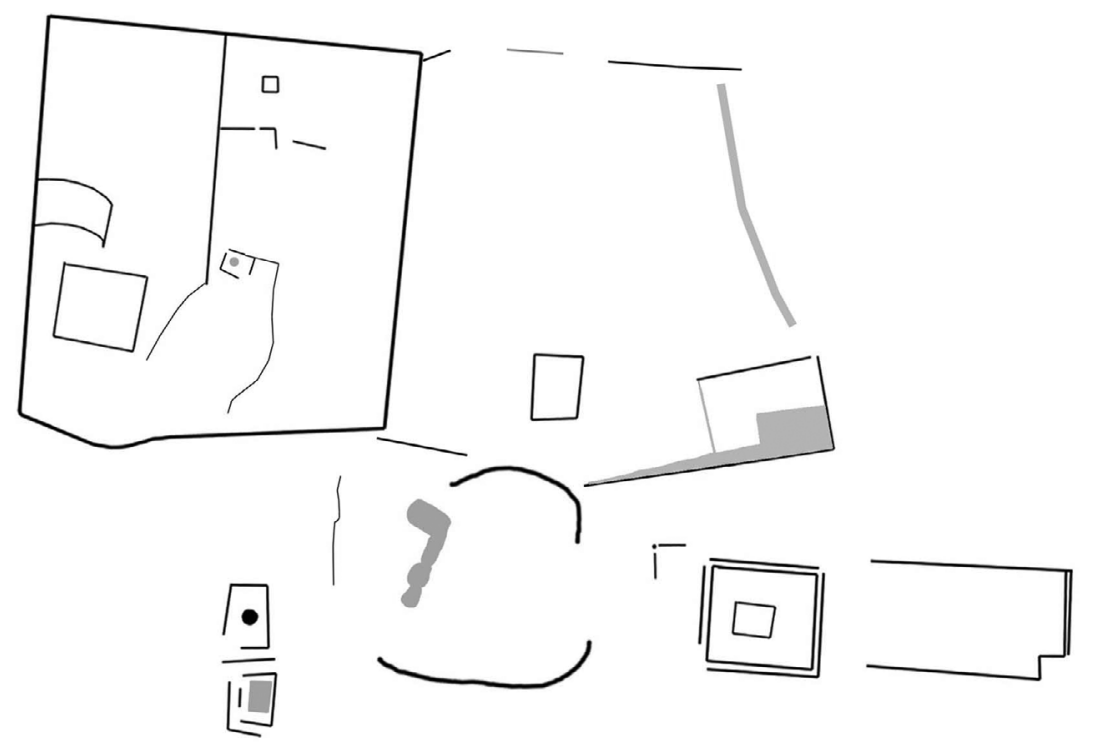

$1000 \mathrm{~m}$.

Fig. 7. Drawing of archaeological features identified in the aerial photograph of the Ban Nong Chaeng site. 
remains and suggested on the basis of the brick size that they were from the Dvaravati period. A small-scale excavation at the site of a lateritic structure of the prang type later yielded a statue of a Prajanaparamita (a deity in Mahayana Buddhism) (Opakul 2000).

Unfortunately, the 1965 FAD report did not specify the precise location of the ruins. Our current investigation was further impeded by the fact that only minor fragments of the clay bricks could be seen on the surface in some areas and that large pieces of laterite bricks of unknown provenance had been reused to decorate the landscape of a nearby temple. Nevertheless, archaeological materials (i.e., monumental decorations, pottery, votive tablets) from the site could be examined in the collection kept at the Ban Nong Chaeng school. Most of the materials are from the Lopburi period; only a few votive tablets can be classified as Dvaravati types. This contradicts statements by previous investigators who argued that the structures of the clay bricks indicated a Dvaravati architectural style. However, similar clay bricks have been found at the monumental ruins at the newly identified sites of Ban Tha Pong, Ban Don Kork, Ban Dong Chueak, and Nong Ya Sai (Fig. 1). Apparently, clay bricks were commonly used in construction at many Lopburi-period sites in the Tha Chin River valley.

Spatial information obtained during our research revealed that there are some interesting features in west-central Thailand that have not been seen in other regions. The 1953 aerial photographs of the area of Ban Don Kork, Suphanburi Province, show a square earthwork enclosure approximately $300 \times 300 \mathrm{~m}$ with a substantial pond, $65 \times 65 \mathrm{~m}$, in the middle (Fig. 8). The enclosure was located east of a large

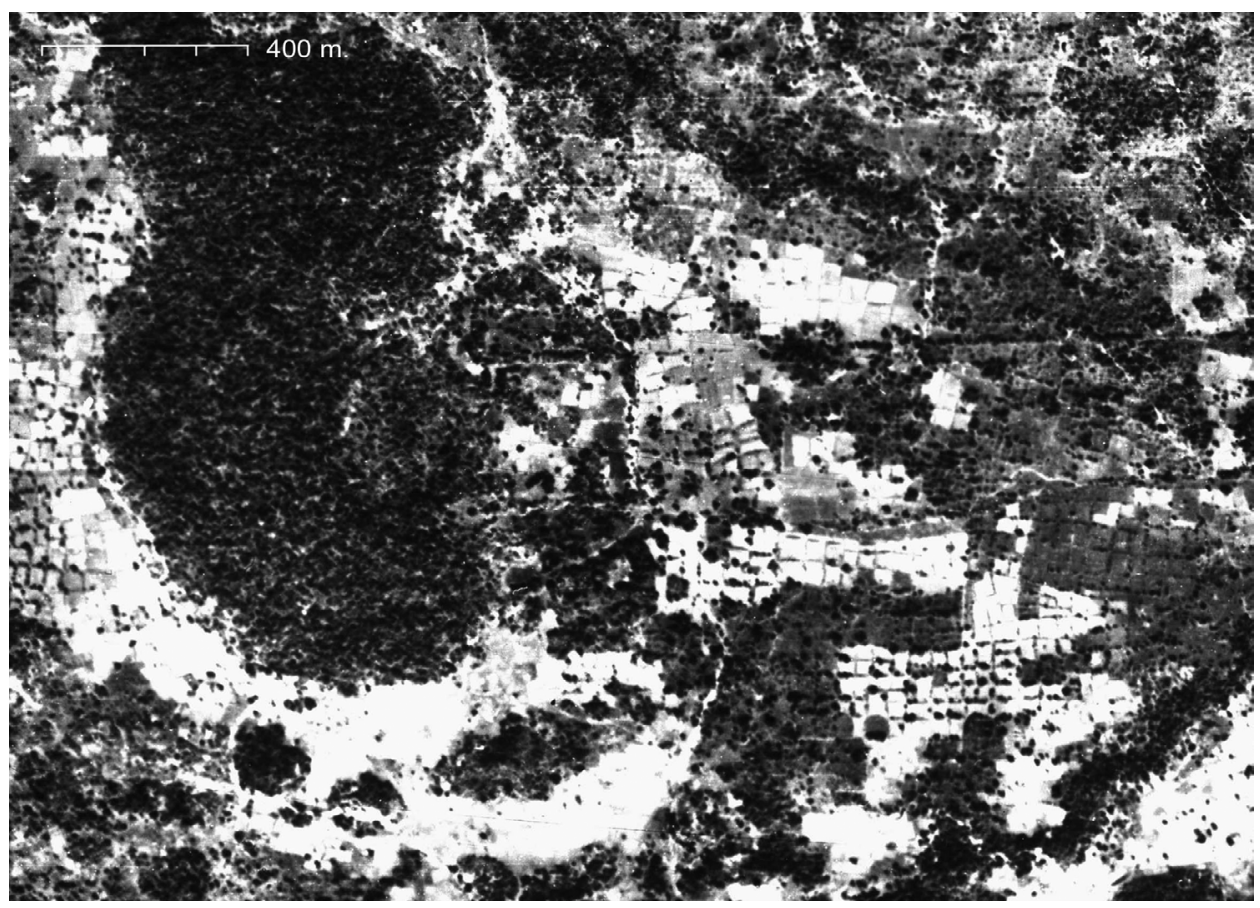

Fig. 8. Aerial photograph of Ban Don Kork (VVWWS M23 AMS 11 Feb 53, 119, 3074). 
natural mound where the village of Ban Don Kork is situated. Local people reported having seen a monumental ruin in the middle of the mound. Ban Don Kork is another looted site. A number of statues relating to Mahayana Buddhism were discovered there, but there is not much to be seen at the site now other than some clusters of potsherds.

Investigating the square enclosure on the ground, we saw that the earthwork was still noticeable. The pond is relatively shallow and contains almost no water during the summer. Near the pond at the southwest corner of the enclosure was a little mound raised about $2 \mathrm{~m}$ above the ground. This looks like a surviving part of the original earthwork that surrounded the pond. There was no other sign of any construction within the enclosure. This feature thus more likely had a ritual than a residential function.

Dating this site is difficult. Enclosure constructions were not known in Dvaravati culture, so the site was probably constructed some time after the eleventh century. Other archaeological evidence, specifically the monumental ruin in the vicinity, indicates a probable thirteenth-century date, but there is no apparent connection between the enclosure and the ruin, so we cannot be certain.

A similar site plan has been identified at Ban Lum Din in Ratchaburi Province, where archaeological evidence for dating is more available. Fortunately, this site has been protected as part of the large registered moated site of Ratchaburi. Construction of modern buildings has not been allowed in this part of the ancient town, so archaeological features have survived reasonably well. The size of the enclosure at Ban Lum Din is approximately $350 \times 350 \mathrm{~m}$. Four ponds can be seen within the enclosure in a 1952 aerial photograph (Fig. 9). No other construction activity within the enclosure is apparent.

A square pond in the middle of the enclosure was surrounded by earthworks. A flattened area may represent a path adjacent to the pond within the earthworks. Two other ponds found at the northeast and southwest corners were rectangular. The fourth pond, located north of the central pond, was small and square. During our ground survey, we noticed a rectangular platform located immediately north of the central pond. Many potsherds were found clustered on the surface. Some potsherds were from thirteenth-century Chinese white-glazed Qingbai wares, while others were identified as Buriram brown-glazed types. There were abundant samples on the surface of fourteenth-century ceramic Chinese brown-glazed and green-glazed types, as well as Ban Bang Poon stoneware types. These surface finds provide verification of the period of site occupation.

Similar constructions have not been found in other regions of Thailand. The composition of the enclosures - their size, shape, orientation, and water features - is reminiscent of the Khmer architectural tradition, however. Khmer architectural layouts were strictly square or rectangular and always oriented north-south and east-west. They often included water features in their architectural plans, usually as a boundary or pond. These water features often had religious associations at particular locations. For example, the arokayasala religious compounds found in northeastern Thailand always had a pond situated at the northeast corner but outside the walled compound.

Places of worship associated with Khmer culture always had at least one tower in the middle. The only known Khmer sanctuary with a pond in the middle is the thirteenth-century Prasat Neak Pean in Cambodia, but even at this location there is a tower built in the middle of the pond. Interestingly, the size of the Cambodian sanc- 


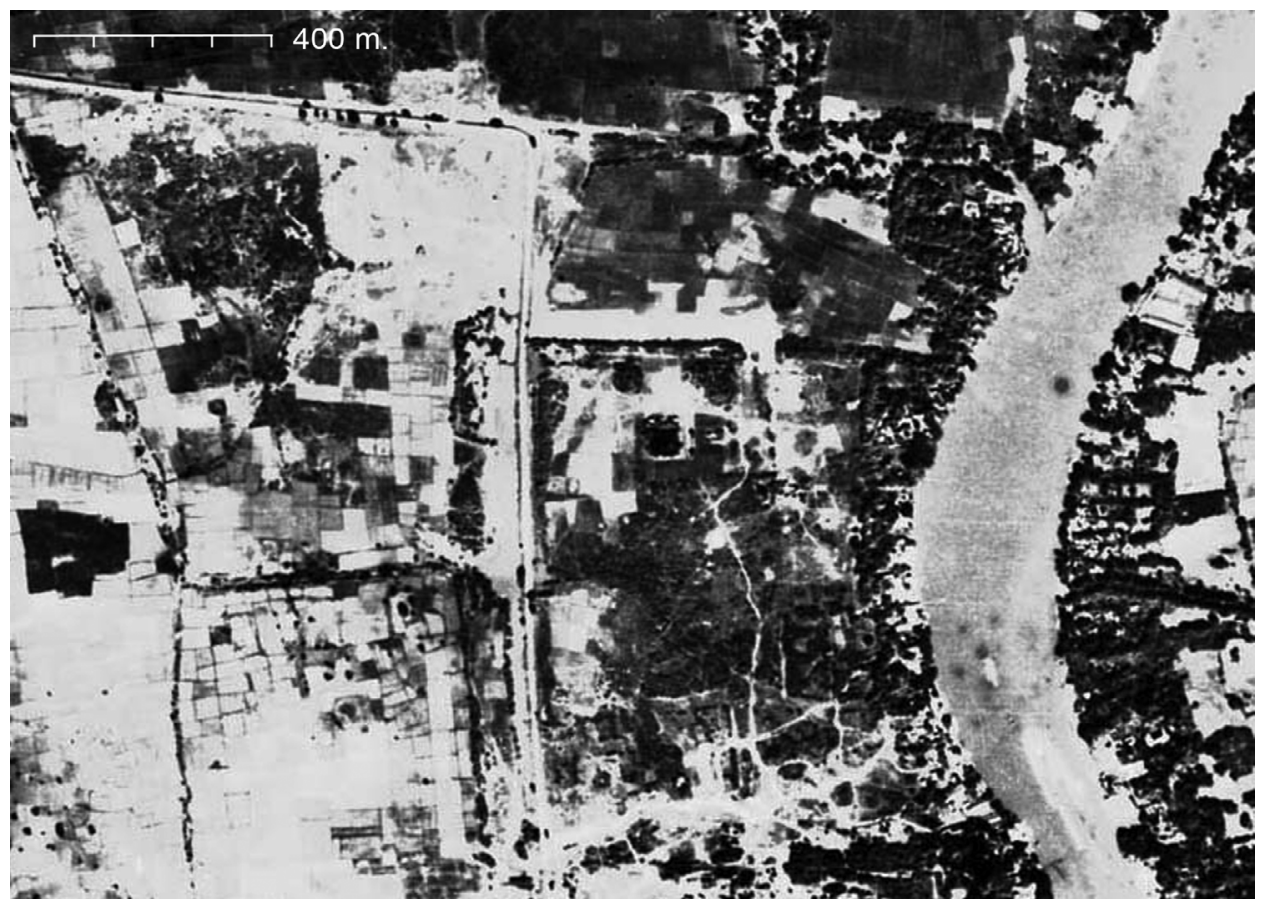

Fig. 9. Aerial photograph of Ban Lum Din (VV WWS M9 AMS 30 Dec 52, 119, 1078).

tuary is $400 \times 350 \mathrm{~m}$ and its pond is $60 \times 60 \mathrm{~m}$. The two sites of Ban Lum Din and Ban Don Kork in west-central Thailand have similarly scaled construction features and similar layouts. The overall structural plan of Prasat Neak Pean was more elaborate, however, with four subsidiary ponds situated on each side of a major pond and linkages between them (Fig. 10). The structure of Prasat Neak Pean has been interpreted as a replication of the mythical pond of Anodard, with its supposedly purified water continually overflowing into four subsidiary ponds. Normally, each part of the structure of ancient Khmer temples would have had a symbolic and culturally meaningful function in relationship to the whole. These functions can usually be interpreted from the decorations and artifacts associated with the place. It is difficult to draw any meaning from the parallels between the structures at Prasat Neak Pean and those found at Ban Lum Din and Ban Don Kork, however, since the archaeological materials necessary for interpretation have not yet been recovered from the latter sites.

As Mahayana Buddhism was imported to Thailand, which had been dominated by Hinayana Buddhism for several centuries, the Dvaravati tradition of constructing urban sites with large moated enclosures was replaced with strict geometrical shapesa square and rectangle with a religious monument situated in the middle. The ancient Khmer tradition of creating artificial lakes or large ponds (baray) also occurred in west-central Thailand. Note that barays were situated outside and immediately to the north of the walls of the sites of Muang Kosinarai and Muang Petchaburi (Fig. 11). A number of villages in the study region carry the name of sra (pond), including Ban Sra, Sra Krachom, and Sra Toey. ${ }^{11}$ Most of these ponds still exist and have been known for several generations. It is not easy to determine the date of construction of these 


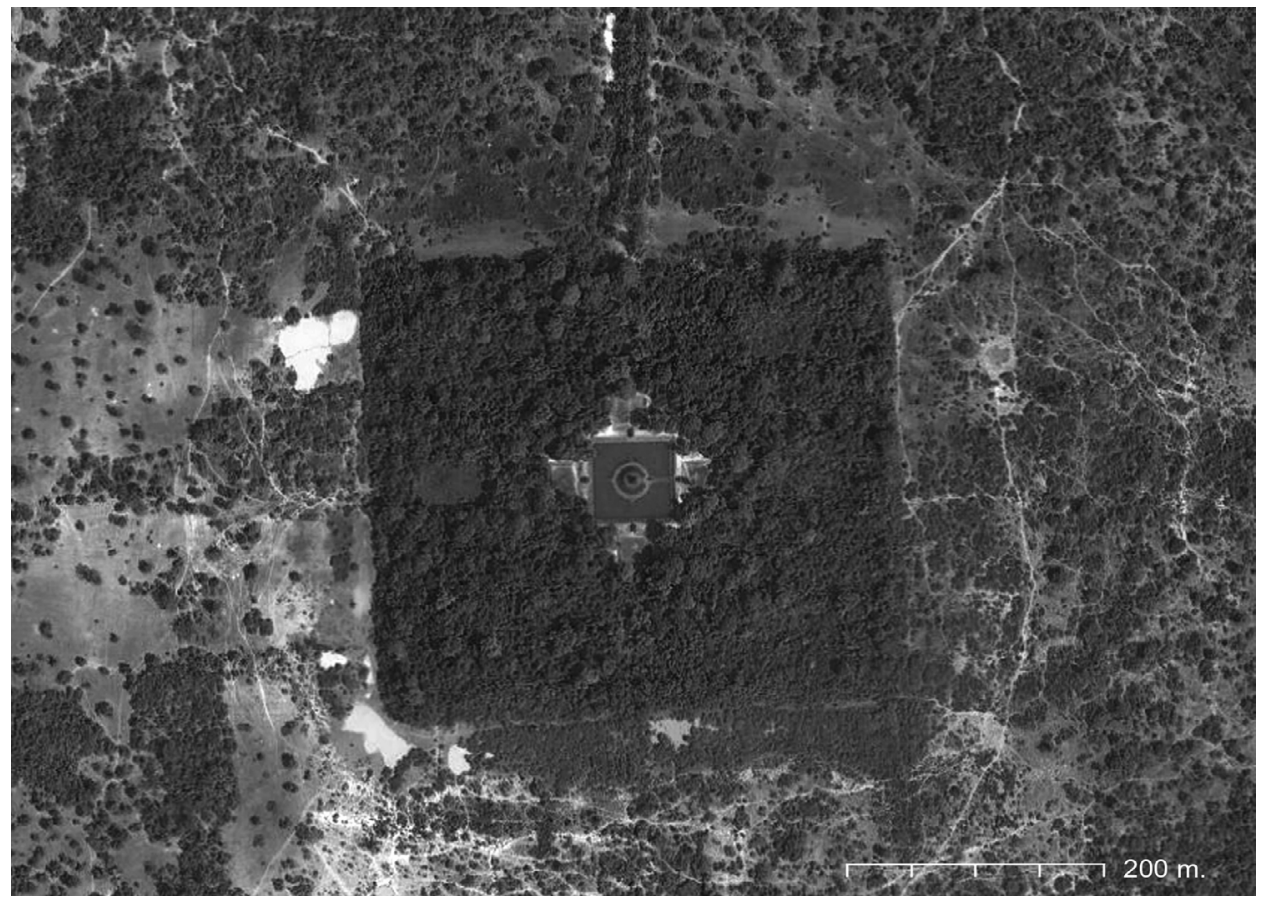

Fig. 10. Satellite image of Prasat Neak Pean, Cambodia (modified from Google Earth image retrieved 30 May 2012).

water features, however, because this form of water management has continued to operate continuously from the past until today.

The unusual characteristics of sites in west-central Thailand may have derived either from selective cultural adoption or from cultural resistance against an intrusive foreign culture. It seems more likely that people in west-central Thailand from the eleventh to thirteenth centuries selectively adopted the exotic Khmer cultural style and blended it with indigenous cultural patterns than that they were forced to acculturate because of political expansion and domination by the Khmer. While there is clear evidence of the strong influence of Khmer culture in west-central Thailand (as seen in the monumental structures at Prasat Muang Singha and Wat Kamphaeng Laeng), local craftsmen seem to have enjoyed significant liberty in melding their artistic styles with foreign design templates.

\section{DISCUSSION: THE CULTURAL DIVERSITY OF POST-DVARAVATI WEST-CENTRAL THAILAND}

Although further fieldwork involving excavation needs to be conducted to clarify the cultural chronology of the Lopburi period in the study region, we believe that the archaeological data obtained in our research has already brought clarity to the regional archaeology, as well as to understanding the early history of Mainland Southeast Asia. Finding archaeological sites with features such as enclosures of earthworks, mounds, and ponds in the study region already suggests there was a change from the 


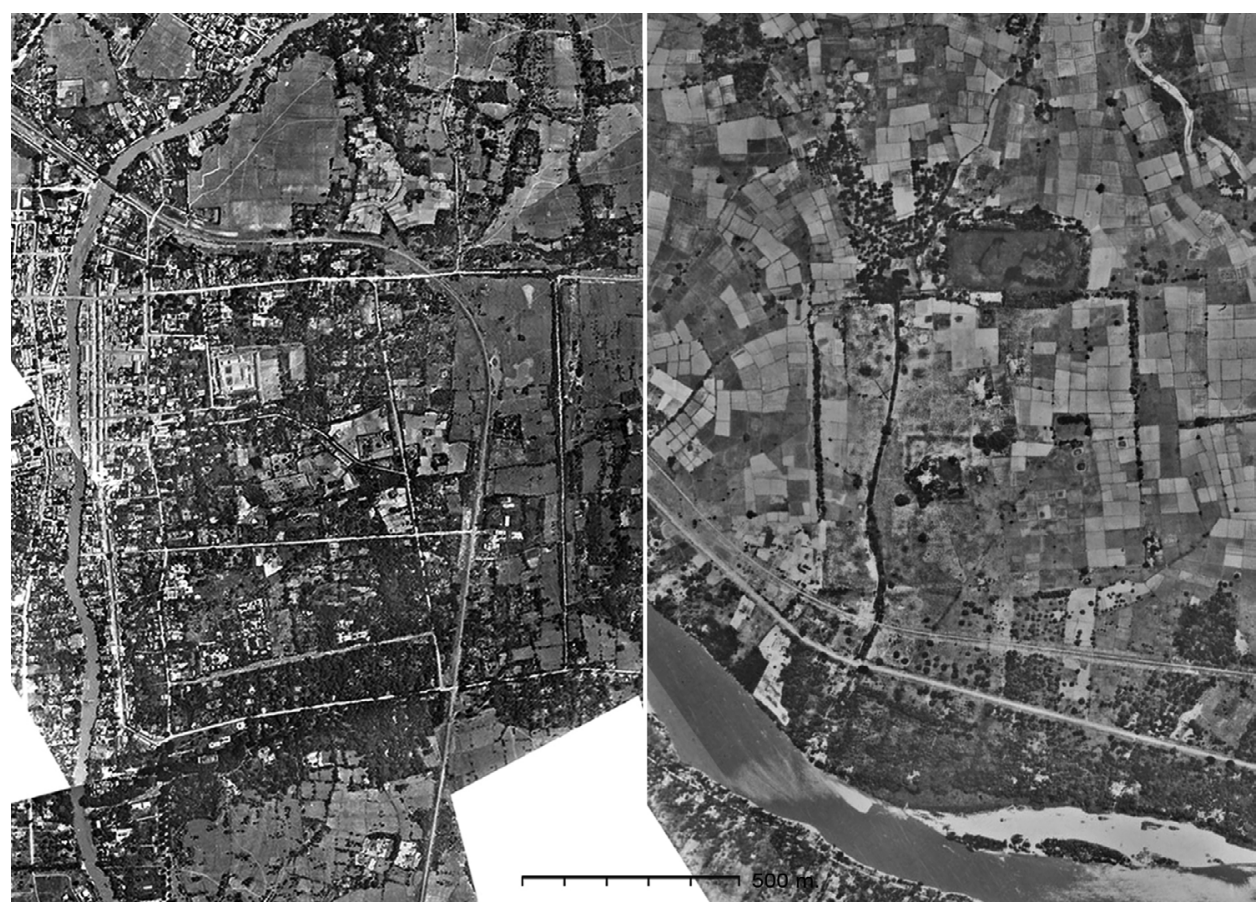

Fig. 11. Aerial photographs of Muang Petchaburi (left) and Muang Kosinarai (right) (modified from Williams-Hunt Aerial Photograph Digital Collections, available at gdap.crma.ac.th).

Dvaravati tradition to favoring the Khmer cultural style. The people of west-central Thailand appear to have modified and adapted Khmer architecture to suit local cultural conventions, however. Certain attributes appear to demonstrate the continuity of a local tradition possibly derived from Dvaravati's cultural zenith.

The new data obtained in this study raise some issues. The first, which we have already discussed, concerns the location of Suvarnapura, one of the towns mentioned in the inscription at Prasat Phreah Khan. Previous scholars have argued that the Noen Thang Phra site was the center of Suvarnapura because of its rich and elaborate artifacts, including a life-size Avarolikesvara statue, enormous stone craft portraying human heads, and abundant stucco decorations. However, this monumental site was rather isolated and the finds were distributed in a small area. We propose that the walled site newly discovered at Ban Nong Chaeng should instead be considered the physical location of Suvarnapura because of its varied and large-scale archaeological features clustered in a complex covering an area with a $2 \mathrm{~km}$ radius. The complex consisted of a large walled site and numerous square and rectangular enclosures of different sizes. Although the site was heavily looted and artifacts were removed from the site before a survey and test excavation could be conducted, the artifacts known to have come from Ban Nong Chaeng are no less significant than those from Noen Than Phra. ${ }^{12}$

It is not the intention to argue here that only sites with walled structures should be considered as potential urban centers. The monumental site at Noen Thang Phra must have been one of the most important sites in the Tha Chin River valley and was 
probably closely related to the site at Ban Nong Chaeng. The likelihood that there was an area of political influence is also suggested by the numerous sites clustered in this subregion, which appear to share some material styles and other archaeological characteristics.

A second point we wish to make concerns site distribution during the Lopburi period. While a significant number of sites were clustered in the Tha Chin River valley, the density of sites was less in the Mae Klong River valley. We recognize that the number of sites reported in this article may not accurately represent the historical total, since many more sites may yet be discovered. However, it may be more significant to compare the variation in the archaeological assemblages of these two subregions than simply compare the number of sites. These variations could have important implications in terms of cultural interaction.

For example, the types of statues preferred for worship are different in the two subregions. Five specimens of rare radiating Avalokitesvara statues made of stone have been found in Thailand, two in Lopburi Province and three in the west-central region of Thailand. All the west-central specimens were found at sites in the Mae Klong River valley: Prasat Muang Singha, Muang Kosinarai, and Wat Kamphaeng Laeng. Numerous four-armed Avalokitesvara statues were also found at Prasat Muang Singha.

Only a small number of four-armed Avalokitesvara statues have been found in the Tha Chin River valley, including a life-size one found at Noen Thang Phra, but a large number of sculptures of Buddha seated under the protection of a naga hood have been recorded in this area. Many of them serve as the principal Buddha statues in temples in Suphanburi Province (Fig. 12). Their original provenance is not known, but it is said by villagers that some of the statues have been at the temples since they were founded, while others were moved from the rubble of ancient monasteries in Suphanburi. Many of the Buddha statues have survived in decent condition, but some have been repaired so often their original features are no longer recognizable. Nevertheless, many of the images have similar facial features. Only small numbers of this type of Buddha images have been discovered in the Mae Klong River valley. These images are smaller and the quality of their craftsmanship does not seem as high as the statues found in the Tha Chin River valley. The type of Buddha image (seated under a naga) found in Suphanburi is also common around Lopburi Province, although some of the statues found there are larger than life-size. Similarities between the cultures of the river valleys in Lopburi and Suphanburi can be expected since the valleys are not far apart, although Lopburi was more obviously politically influenced by the Khmer. ${ }^{13}$

Another difference between the Mae Klong and the Tha Chin River valleys is in the construction materials used. ${ }^{14}$ While monuments in the Mae Klong River valley were built with laterite bricks, those in the Tha Chin River valley in Suphanburi were constructed mainly of clay bricks. Full-sized clay bricks found at these Lopburi-period sites happen to be a similar size (approximately $36 \times 18 \times 9 \mathrm{~cm}$ ) to the clay bricks used in Dvaravati-period construction, which is generally considered to have passed its peak after the eleventh century. Laterite bricks were used in Suphanburi for foundations and the core stone decorations on prang.

Choice of building materials might have been a matter of local availability, as well as cultural preference in brick commissioning and craftsmanship. Most thirteenthcentury structures found in Thailand were made of laterite, covered with plaster, and decorated with stucco. Examples include the buildings at Prasat Muang Singha and 


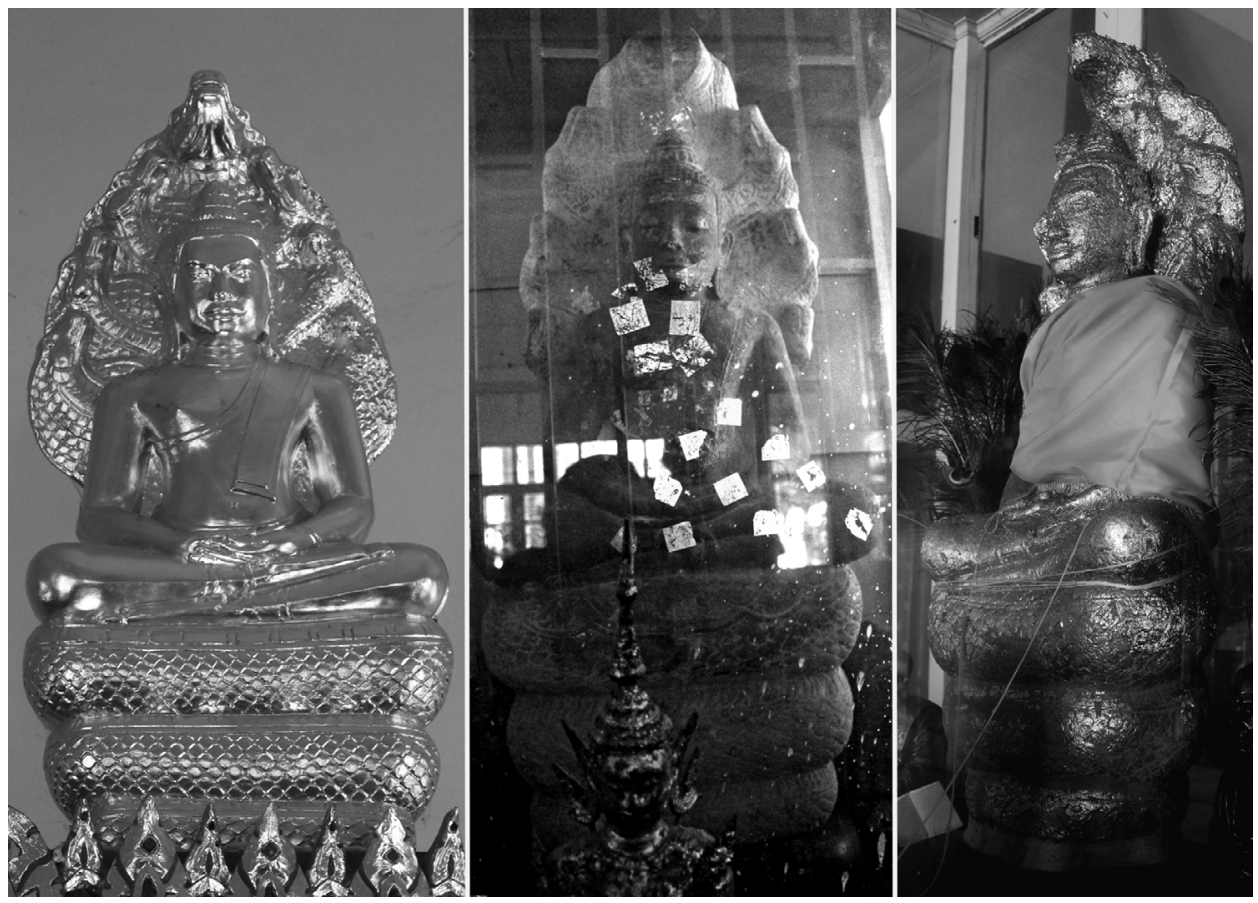

Fig. 12. Buddha images from the Lopburi period. Left to right from the temples of: Wat Phra Loy, Wat Wang Hin, and Wat Klong Cha Do.

arokayasalas and dhammasalas in the northeastern region. Clay bricks were used for construction at an earlier date of the ancient Khmer period, between the tenth and eleventh centuries. Apparently the brick sizes described in Charernsupkul's study (1981) of buildings from that earlier date in the northeastern region of Thailand are similar, but slightly thinner than those used in the thirteenth-century monuments in Suphanburi. Prang Khaek, a tenth-century Hindu temple in Lopburi, is a good example of the combining of Khmer and Dvaravati architectural techniques. Despite being constructed in the Khmer style, the brick sizes are closer to those of Dvaravati bricks, although they have been fired better (Charernsupkul 1981:141-142). Construction techniques such as bricklaying cannot be inspected at any of the architectural ruins in Suphanburi, so it is not possible to make a comparison with those in the east-central or northeastern regions.

While certain features of Dvaravati culture continued in the Tha Chin River valley after the eleventh century, the archaeological materials found at sites such as Muang Kosinarai, Wat Maha That Ratchaburi, Wat Kamphaeng Laeng, and Prasat Muang Singha in the Mae Klong River valley appear to illustrate the strong influence of the Khmer Bayon. ${ }^{15}$ The historical site of Prasat Muang Singha shows the earliest indications of having been a large community, but it is not known why the most western Bayon tower was erected there. Prasat Muang Singha is situated on flat terrain along the Kwai Noi River, bordered by mountain ranges. Another rectangular walled site $5 \mathrm{~km}$ to the southeast of Prasat Muang Singha is known as Muang Krut. ${ }^{16}$ The evidence 
from Muang Krut is rather fragmented. It is not known if construction was abandoned before it was completed (perhaps because of a drought in the area) or if it was completed but then most of the remains were later removed (Kwanyuen 1994).

Northwest of Prasat Muang Singha, the strip of flat terrain becomes much narrower and mountains much higher. Heading up the Kwai Noi River leads to the Thong Pa Phum area, which used to be a great source for tin mining. Farther north and east, the river reaches a plateau near the Three Pagodas Pass on the Thai-Myanmar border. This pass was used repeatedly over the centuries to move armies. Given this topography and its abundant natural resources, thirteenth-century Prasat Muang Singha must have played a significant economic role in the region. It is also likely that the Khmer had a political influence on the Mae Klong River valley and environs. Suksvasti (1983a, 1987b) argues that the rapid and drastic transformation in architectural style and religious beliefs that occurred in the Mae Klong River valley after the eleventh century could not have been solely the result of voluntary cultural change.

Historical records from various sources have indicated a relationship between Angkor and its neighbors to the west. The inscription from Banteay Chmar mentions an occasion when King Jayavarman VII and his son resisted an army from the west (Wright 2006). It is not clear how far west the inscription refers to; it could have been describing a long journey reaching Pagan, Pagu, or Thaton, or a much shorter trip to the immediate area west of the Chao Phraya valley. More direct evidence is needed to clarify this matter. Our point, however, is that west-central Thailand would not have been overlooked by the Khmer rulers either as a valuable source for commodities such as tin and forest products or as a strategic area important for their political security.

\section{RESEARCH PROSPECTS}

The overall trend in early state formation was toward political consolidation into expanding states and empires in Mainland Southeast Asia from the middle of the first millennium to the early second millennium A.D. However, various geographic regions saw the rise of dominant polities such as Dvaravati and Khmer at different times in their history. Each region had its own resources and its people had distinct skills and knowledge that allowed them to expand their influence and power. We assert that a deeper understanding of regional archaeology is therefore necessary for developing a multidimensional understanding of the social, political, and economic transformations of early states in Southeast Asia.

Our research has demonstrated that west-central Thailand was not a cultural, political, or economic backwater after the decline of Dvaravati. The inhabitants of this region not only had continued and sustained interactions with people in other regions, but also actively participated in the socioeconomic changes and political reconfigurations that swept Mainland Southeast Asia after the eleventh century. Ancient communities adjusted to the fading of the once-prominent Dvaravati civilization. Rising powers such as Pagan to the west and Angkor to the east surpassed Dvaravati in terms of their economic reach and political expansion. The economic system of west-central Thailand certainly changed as its inland areas became more economically desirable. The inter-regional economies of Southeast Asia must have encouraged a vigorous exchange in technology and a high demand for natural resources. At the 
same time, military competition related to social conflict, economic rivalry, and possibly competing claims of cultural dominance must have increased considerably, so that conflicts among the regions became inevitable.

The west-central region of Thailand might be considered a marginal area or a mere buffer zone between the two most powerful political forces of Angkor and Pagan. However, in order to develop a fuller picture of early Southeast Asian history, one should take into account the historical archaeology of the region in a wider context that goes beyond ascendant centers of power to examine the so-called peripheries. We can then discern the impact of different cultures upon one another. The study region discussed in this article provides a good example of how societies conducted social and cultural activities far from major economic centers, and in turn had an impact on those centers. The evidence obtained during our research demonstrates that ancient communities in west-central Thailand made cultural adjustments by selectively adopting new cultural forms and technologies to suit their existing cultural and material styles.

New technologies enable archaeologists to direct their attention to questions that could not have been answered earlier. Archaeology has benefited recently from the application of innovative technology. Space technology such as remote sensing has certainly contributed to our ability to acquire new data, especially in regions such as west-central Thailand where historical features have been moved or erased from the landscape by modern development. This study recorded numerous features constructed by human beings at post-Dvaravati sites that were detected from aerial photographs; others were discovered during fieldwork on the ground. The two approaches are most useful when conducted in tandem, since an obvious feature on the ground may not necessarily show up in aerial or satellite images. Likewise, large-scale features that are clearly man-made (such as ditches or walls) that can be seen in aerial or satellite images are not always traceable when walking on the ground. Any structures identified using remote sensing technology need to be further investigated through detailed excavations to determine their functions and dates. Archaeologists must beware of interpreting aerial or satellite images to fit with other data or expectations. A feature seen in an aerial photograph, for example, can appear to be a kiln, building foundation, or another type of monumental ruin. Intensive fieldwork and trial excavations must be conducted at the site to clarify the actual purpose of the feature. With these caveats in mind, this article has demonstrated the value of using multipronged archaeological methods in reconstructing the complexities of cultural contacts, social interactions, political power dynamics, and economic strategies in early Southeast Asian state centers and peripheries.

\section{ACKNOWLEDGMENTS}

We would like to express our gratitude to Geo-Informatics and Space Technology Development Agency (GISTDA) for funding this project and providing useful spatial information. Our grateful thanks go to members of the Fine Arts Department of Thailand for their collaboration. We also owe gratitude to Arunsak Kingmanee at the Second Regional Office of Fine Arts in Suphanburi, the Fine Arts Department, and Rungroj Piromanukul at Ramkhamhaeng University for their expertise in iconography and Pariwat Thammapreechakorn, Director of Southeast Asian Ceramics Museum at Bangkok University, for his kind help with identifying ceramics. 


\section{NOTES}

1. The living quarters for pilgrims were likely situated nearby the stone towers. Presumably constructed from organic materials such as wood, they have not survived until the present day.

2. A Dhammaraja is a king ruling according to the teachings of the Buddha.

3. Suksvasti (1983b) suggests that this could indicate political unrest in the Khmer Empire.

4. Not only place-names have to be interpreted from this text; the specific types of statues built in the towns remains ambiguous. It is still uncertain whether they were in the form of radiating Avalokitesavara figures, Buddhas seated under a naga (serpent), or some other form (Diskul 1966; Woodward 1994-1995).

5. While we know about the materials used for constructions associated with high-ranking people, little is known about the everyday lives of ordinary people during the Lopburi period. We do not know much about trade interactions, social class differences, or different ethnic groups living at these sites. Pottery is the most common and datable type of artifact found for the Lopburi period, including the brown glazed ceramics and porcelains typical of the Chinese Song and Yuan dynasties. Local earthenwares and stonewares are abundant at all Lopburi-period sites. However, the regional characteristics of these cultural materials and their chronology are not yet known.

6. Because of space limitations, the major sites of the region that have already been well studied will not be examined in detail here.

7. We believe there are more sites to be discovered in the region, but further investigation was limited by time constraints on the research reported here.

8. Since as professional archaeologists we would like to preserve sites from further looting and destruction, we recognize the irony of expanding our database of surveyed sites based on information provided from the antiquities trade.

9. These and other aerial photographs discussed in the article are conserved in the archives of the Royal Thai Survey Department.

10. Other major religious sites in the region appear to have such features also.

11. Thai village names were often derived from the most dominant feature of the landscape.

12. As noted earlier, some artifacts have been kept at a school museum near the site. Other valuable objects such as bronze statues and votive tablets have been published in antiquities trade magazines (Opakul 1973).

13. The only direct evidence of their relationship is that Suvarnapura (modern Suphanburi) was mentioned after Lavodayapura (modern Lopburi) in the Prasat Phreh Khan inscription. Written records of later periods refer to Lopburi and Suphanburi as co-existing political entities (Vallibhotama 1997).

14. Other than those sites retaining identifiable structures like Prasat Muang Singha and Wat Kamphaeng Laeng, the monumental styles of other ruin sites in the study region are unknown. During the field survey additional sites have been identified such as those at Ban Dong Chueak, Ban Don Kork, Ban Tha Pong, Nong Ya Sai, and Wat Sra Kratiem. Most of these are in Suphanburi Province, except for the last one, which is in Nakorn Pathom Province.

15. Since some Dvaravati decorations remain at Muang Kosinarai, Wat Maha That Ratchaburi, and Wat Kamphaeng Laeng, it is plausible that these sites derived from the major Dvaravati sites of Pong Tuk, $\mathrm{Ku}$ Bua, and Thung Sethi, respectively. There is no Dvaravati evidence at Prasat Muang Singha.

16. Muang Krut was named after the fragmented remains of a sandstone sculpture of a garuda (a large mythical creature, half man half bird).

\section{REFERENCES CITED}

BARRAM, ANDREW

2003 Dating “Dvaravati.” Indo-Pacific Prehistory Association Bulletin 23:59-62.

Briggs, Lawrence Palmer

1951 The Ancient Khmer Empire. Bangkok: White Lotus Press.

Charernsupkul, Anuvit

1981 The Structure Types and Pattern Bonds of Khmer and Srivijayan Brick Architecture in Thailand [in Thai]. Bangkok: Thai Khadi Research Institute, Siam Society and Jim Thompson Foundation.

Chiachanphong, Phiset

1987 Muang Singha and Prasat Muang Singha on the Kwai Noi was not Khom (Khmer) [in Thai]. Art and Culture 8(6): 106-113.

Chulachomklao Royal Military Academy [CRMA]

2012 e-Culture for GMS Project Phase II. e-Culture Map Server (website accessed 17 May 2012). URL: http://larp.crma.ac.th/eculture/. 
Damrong Rajanubhab, HRH Prince

1954 Tales of Antiquities [in Thai]. Bangkok: Fine Arts Department (FAD).

Damrongsiri, Phenphan

1988 Radiating Lokesvara from an Excavation at Prasat Wat Khamphang Laeng [in Thai]. Museum Journal 1(6): 27-31.

Diskul, Subhadradis, Prince

1966 Stone inscription from Prasat Phreah Khan of Javavarman VII [in Thai]. Silpakorn 10(2): 52-62.

Fine Arts Department [FAD]

1965 Unpublished Internal Memorandum of the Archaeological Office Division 2 [in Thai]. Suphanburi: Fine Arts Department.

1986 Inscriptions in Thailand, vol. 4: Khmer Inscriptions of twelfth-thirteenth centuries [in Thai]. Bangkok: National Library of Thailand.

1987 Report of Archaeological Work at Historical Site of Prasat Muang Singha [in Thai]. Bangkok: Fine Arts Department.

FINOT, LOUIS

1966 Radiating Bodhisattva. (Translation of Lokeçvara en Indochine, Etudes Asiatiques 1(1925) : 242244.) Trans. Prince Subhadradis Diskul [in Thai]. Silpakorn 10(2) :46-51.

Hirth, Friedrich, and Rockhill, W. W., eds. and trans.

1911 Chau Ju-Kua: His Work on the Chinese and Arab Trade in the Twelfth and Thirteenth Centuries, Entitled Chu-fan-chi. St. Petersburg: Imperial Academy of Sciences.

Juntawit, Nuttapatara

1986 Artifacts from Prasat Muang Singha [in Thai]. Silpakorn 30(3):30-54.

KaeOKlai, Cha-EM

1985 Inscriptions of King Jayavarman VII. Bangkok: National Library of Thailand, Fine Arts Department.

KwANYUEN, SATHAPORN

1994 Special report on Muang Krut [in Thai]. Silpakorn 7(3):4-9.

Mackay, Richard, AND Sharon Sullivan

2008 Angkor: Heritage Values and Issues. http://acl.arts.usyd.edu.au/angkor/lwh/index.php?option $=$ com_content\&task= view\&id=241\&Itemid=0 (retrieved 4/3/2011).

MANKhong, SunisA, ED.

1995 List of Ancient Monuments in Archaeological Office Division 2 [in Thai]. Bangkok: Fine Arts Department.

Office of the Prime Minister of Thailand [OPM]

1970 Records of Inscriptions, part 4: Evidence from the Regions of North, Northeast, East and Centre of Thailand [in Thai]. Bangkok: Office of the Prime Minister of Thailand.

Opakul, Manus

1973 Votive Tablets from Ancient Hoards in Suphanburi [in Thai]. Phra Nakorn: Silpabunnakarn.

2000 Ancient towns of Lopburi period in Suphanburi Province [in Thai]. Muang Boran 26(3): 71-78.

Piromanukul, Rungroj

2004 Arogayasala: The hospitals of Jayavarman VII. Muang Boran 30(3) : 15-54.

Pryce, T. O., and M. J. Albrams

2010 Direct detection of Southeast Asian smelting sites by ASTER Remote Sensing Imagery: Technical issues and future perspectives. Journal of Archaeological Science 37:3091-3098.

Suksvasti, M. R. Suriyavudh

1983a Prasat Muang Singha [in Thai]. Muang Boran 9(2):90-103.

1983b Prasat Muang Singha [in Thai]. Muang Boran 9(3):102-111.

1987 a Noen Thang Phra: Khmer ruins (Bayon style) in Suphanburi [in Thai]. Muang Boran 13(4) : 23-32.

$1987 b$ Prasat Muang Singha and political power of King Jayavarman VII [in Thai]. Art and Culture $8(8): 44-48$.

Theerajaruwan, Aphisithi

2009 The Royal Roads of King Jayavarman VII or mere embankments [in Thai]. Art and Culture 31(2) : 40-45. 
Vallibhotama, Srisakara

1981 Debates in the Study of Thai History [in Thai]. Bangkok: Muang Boran.

1983 Neun Thang Phra: Architectural remains of Mahayana Buddhism [in Thai]. Muang Boran 9(2): 46-52.

1997 Ancient Cities of Thailand [in Thai]. Bangkok: Muang Boran.

WeEraprajak, KongKaew

1987 Prasat Muang Singha Inscription [in Thai]. Silpakorn 31(1) :50-54.

WilaikAEO, JARUEK

1991 Wat Khamphaenglaeng [in Thai]. Muang Boran 17(4) : 103-110.

Woodward, Hiram W., Jr.

1994/ The Jayabhuddamahanaths images of Cambodia. The Journal of the Walters Art Gallery 1995 52/53:105-111.

WRight, MichaEL

2006 "A Dark Age" or gap in Siam history [in Thai]. Art and Culture 27(11):123-131.

\begin{abstract}
This article presents the results of recent research on the historical period of west-central Thailand between the eleventh and thirteenth centuries. At this time Dvaravati was in a stage of decline while the prominent rivals of Pagan and Angkor began to prosper. The construction of stone sanctuaries in the Bayon style in west-central Thailand has caused serious debate regarding the influence of Jayavarman VII over that part of Thailand. However, the main point of the present study is that the successors of Dvaravati can be considered to have played a significant part in the socio-economy of that period. This research explores the landscape of the study region using remote sensing techniques as well as carrying out conventional methods of fieldwork. New discoveries and current evidence are discussed, along with some issues concerning the archaeology of the postDvaravati, pre-Sukhothai transitional period (c. A.D. 1100-1300). West-central Thailand is believed to have been an economically desirable land with rich resources throughout its history. It is hoped that this work will contribute to the understanding of the social changes after the Dvaravati period when the economic power shifted to other parts of Mainland Southeast Asia. KeYwords: west-central Thailand, Jayavarman VII, Bayon, post-Dvaravati, remote sensing technology, landscape archaeology, Khmer influence.
\end{abstract}

